\title{
Radiation recall after capecitabine in a patient with recurrent nasopharyngeal carcinoma: a case report
}

\author{
Victor Lee ${ }^{1,2^{*}}$, Ka-On Lam $^{1}$, Dora Kwong ${ }^{1}$ and To-Wai Leung ${ }^{1}$
}

\begin{abstract}
Background: Capecitabine has been commonly used in recurrent or metastatic nasopharyngeal carcinoma. However, radiation recall after capecitabine for nasopharyngeal carcinoma has not been reported.

Case presentation: We report the case of a 64-year-old Chinese woman with locoregionally advanced nasopharyngeal carcinoma previously treated with induction chemotherapy followed by concurrent chemoradiation 6 years ago. She developed cervical, mediastinal, and abdominal nodal relapses 14 months later. She then received capecitabine with initial excellent tumor response for 1 year but disease recurrence was noticed at the peripancreatic nodal region, which was successfully treated with concurrent chemoradiation with capecitabine. Unfortunately, she developed progressive erythema of the face and neck region at exactly the previous irradiation site for her initial nasopharyngeal carcinoma, 2 months after taking capecitabine. She initially ignored it, but it became more confluent and serious. Eventually, a facial skin biopsy was performed showing nonspecific chronic inflammation only. The diagnosis was most likely radiation recall phenomenon since capecitabine was the only drug she received before development of this dermatological manifestation on her previously irradiated face and neck. Treatment was conservative and supportive albeit with no significant clinical improvement.
\end{abstract}

Conclusions: Radiation oncologists should be aware of this potential risk of capecitabine, especially when it is administered for a long period of time.

Keywords: Capecitabine, Intensity-modulated radiation therapy, Nasopharyngeal carcinoma, Radiation recall

Abbreviations: DNA, Deoxyribonucleic acid; EBV, Epstein-Barr virus; IMRT, Intensity-modulated radiation therapy; NPC, Nasopharyngeal carcinoma; PET-CT, Positron emission tomography with integrated computed tomography; SMART, Simultaneous Accelerated Radiation Therapy

\section{Background}

Radiation recall is a rare and acute dermatological condition typically occurring at the site of previous radiation therapy, after administration of a certain type of oral or intravenous medication particularly chemotherapeutic agent(s) or, less likely, targeted therapies [1-4]. Skin is the most common site of manifestation with incidence between 6 and $11 \%$ according to previous literature [5]. The time lapse between previous radiation therapy and the onset of radiation recall after use of the causative

\footnotetext{
* Correspondence: vhflee@hku.hk

'Department of Clinical Oncology, Queen Mary Hospital, Li Ka Shing Faculty of Medicine, The University of Hong Kong, Hong Kong, Hong Kong

${ }^{2} 1 / F$, Professorial Block, Queen Mary Hospital, 102 Pokfulam Road, Hong Kong, Hong Kong
}

drug varies, ranging from days to months or even many years after the last radiation therapy [2, 4-6]. It has also been recently postulated that the severity of radiation recall is associated with the dose of the medication. Treatment would be most likely conservative with modest improvement after use of topical or systemic glucocorticoids, but the condition may persist even if the causative drug is withdrawn, especially when there is irreversible amage to the dermis.

Capecitabine, a prodrug of 5-fluorouracil, has been cancers and thus all patients who were previously reported to suffer from radiation recall after capecitabine 
had their primary tumors in these tracts [7-11]. Capecitabine, in fact, is also active for nasopharyngeal carcinoma (NPC), an endemic disease in Southern China including Hong Kong, as shown in previous phase II and III studies [12-16]. Some case reports were published on radiation recall in patients previously treated for their head and neck cancers [17-19]. To the best of our knowledge, no report has been published on radiation recall after use of capecitabine for NPC. We here report the case of a patient who suffered from radiation recall phenomenon at her faciocervical region previously irradiated for her NPC, after taking capecitabine for her more recently developed cervical, mediastinal, and abdominal nodal relapse 1 year after radical chemoradiation for her NPC.

\section{Case presentation}

A 64-year-old Chinese woman was diagnosed to have stage IVB T1N3bM0 undifferentiated type of nasopharyngeal carcinoma (NPC) 6 years ago. Pretreatment plasma Epstein-Barr virus (EBV) deoxyribonucleic acid (DNA) was 827 copies $/ \mathrm{mL}$. She received induction chemotherapy consisting of one cycle of cisplatin and 5fluorouracil and two more cycles of carboplatin (areaunder-the-curve value 5) plus 5-fluorouracil in view of her deteriorating renal function, followed by radical chemoradiation using carboplatin concurrent with intensitymodulated radiation therapy (IMRT) with 70 Gy in 33 fractions to the gross primary tumor and neck nodes and 66 Gy in 33 fractions to the high-risk primary and neck nodal regions, all over 6.5 weeks delivered by Simultaneous Accelerated Radiation Therapy (SMART) technique completed 5 months later. Posttreatment plasma Epstein-Barr virus deoxyribonucleic acid (EBV DNA) became undetectable at 8 weeks after IMRT. Unfortunately, her disease relapsed 14 months later with lymph node metastases to the left supraclavicular fossa and the right superior mediastinal region, together with a distant lymph node metastasis at the peripancreatic region revealed by [18 F]fluorodeoxyglucose positron emission tomography with integrated computed tomography (PET-CT) (Fig. 1). Plasma EBV DNA rose to 338 copies $/ \mathrm{mL}$. In view of distant metastasis, she started capecitabine at $1000 \mathrm{mg} / \mathrm{m}^{2}$ twice daily from day 1 to 14 and every 3 weeks afterward and titrated up to $1250 \mathrm{mg} / \mathrm{m}^{2}$ twice daily from day to 1 to 14 every 3 weeks from cycle 3 onward with a significant drop of plasma EBV DNA to 0 copies $/ \mathrm{mL}$ after taking capecitabine for 7 months. She continued capecitabine up to 1 year until further disease progression with increasing in size of the peripancreatic lymph node metastasis with plasma EBV DNA elevation to 64 copies $/ \mathrm{mL}$. In view of the solitary peripancreatic nodal disease, she received conformal radiotherapy (50 Gy in 25 fractions over 5 weeks)

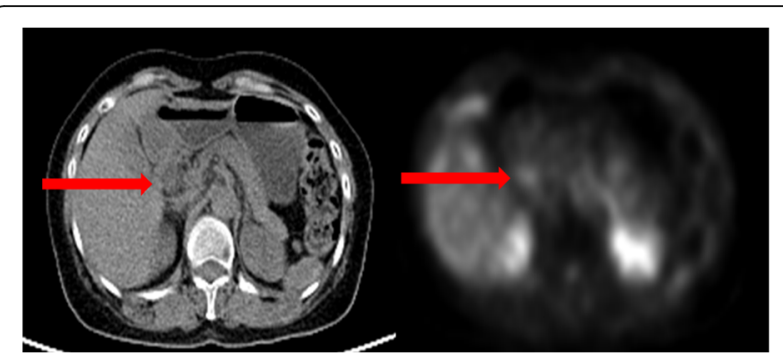

Fig. 1 Positron emission tomography with integrated computed tomography image showing the hypermetabolic peripancreatic nodal relapse (red arrow)

to the peripancreatic lymph node concurrent with capecitabine $825 \mathrm{mg} / \mathrm{m}^{2}$ twice daily and 5 days a week on radiotherapy days only. Plasma EBV DNA dropped to 0 copies/mL and her PET-CT scan 9 months later confirmed complete metabolic response of the peripancreatic lymph node. Capecitabine was then stopped after the complete response demonstrated in this latest PETCT scan. Unfortunately, she noticed that her face gradually developed progressive erythema and increasing warmth with relative sparing of the nostrils and perinasal region 2 months after taking capecitabine. It was initially ignored by our patient until the skin erythema became more confluent and prominent at the irradiation site of the previous IMRT for her initial NPC (Fig. 2a-c). It did not subside with capecitabine cessation as well as application of emollients, topical and oral steroids, and even antibiotics. A skin biopsy showed nonspecific inflammation only. As the dermatological manifestation was confined to her face and neck only and she had not received any other oral or topical medication except capecitabine, radiation recall was the most likely underlying diagnosis to account for her current skin condition. She received a course of laser therapy prescribed by a private dermatologist but the skin condition prevailed (Fig. 2d). Unfortunately, her facial skin condition has been persistent for more than 4 years though no further evidence of NPC recurrence has been noted so far.

\section{Discussion}

Capecitabine is rarely used as part of systemic chemotherapy in head and neck squamous cell carcinoma but it is more commonly used in breast, esophageal, gastric, colorectal, and pancreatic cancers [7-11]. On the other hand, capecitabine is one of the most commonly prescribed regimes for recurrent and metastatic NPC, a separate disease entity from head and neck squamous cell carcinoma based on its different etiology and geographical epidemiology, since the response rate ranges from $23.5 \%$ as monotherapy to $62.5 \%$ when used in combination with cisplatin [12-15]. More recently, capecitabine has also been found efficacious as induction 

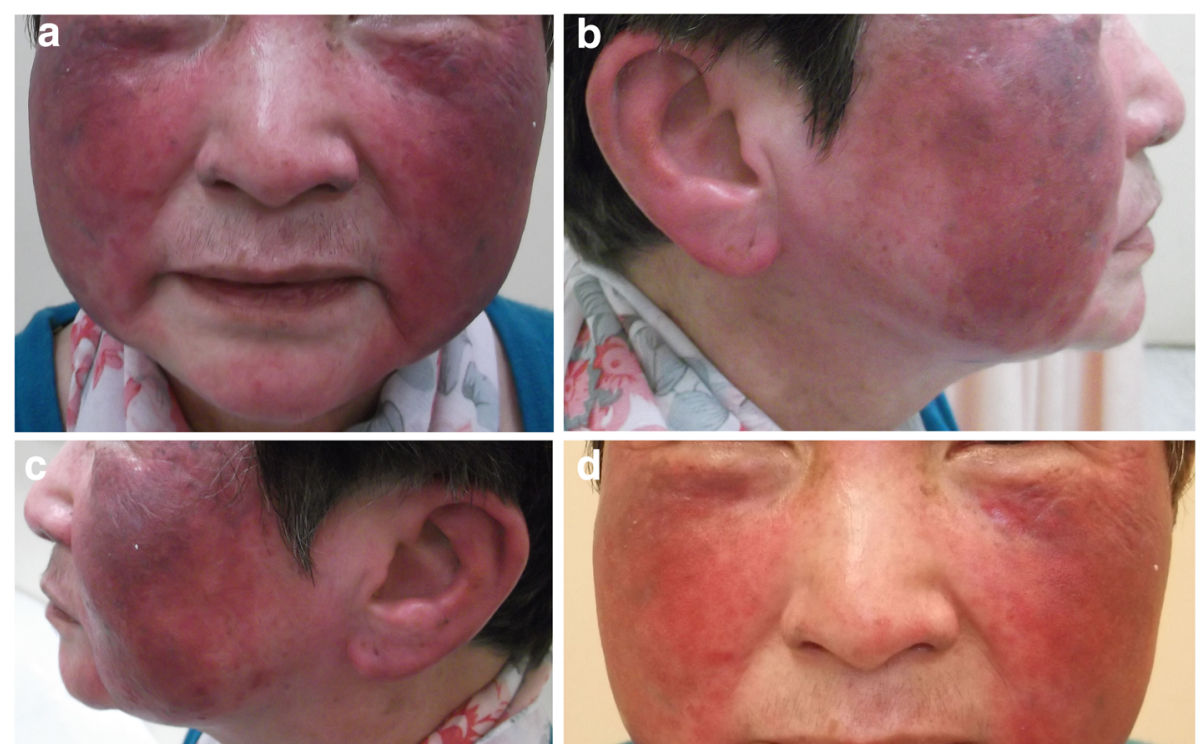

Fig. 2 Radiation recall phenomenon after capecitabine for our patient who suffered from recurrent nasopharyngeal carcinoma. a Forehead and face. b Right face and ear. c Left face and ear. d Persistent appearance after laser therapy

chemotherapy followed by concurrent chemoradiation in a phase III randomized controlled trial conducted in Hong Kong [16]. Radiation recall related to prior use of capecitabine has been reported in patients with breast and pancreatic cancers [20-22]. However, it has not been reported so far in head and neck cancers, including NPC. The exact pathophysiology for radiation recall phenomenon remains to be deciphered. Vascular damage, epithelial stem cell sensitivity or hypersensitivity to chemotherapeutic agents have been postulated as the underlying mechanisms [5, 23]. More recently, thymidine phosphorylase, a potent angiogenic factor was shown to be associated with the development of radiation recall after capecitabine use [22, 24]. Sawada et al. revealed that external radiotherapy induces thymidine phosphorylase and it enhanced the efficacy of capecitabine in human cancer xenografts [25]. Thymidine phosphorylase produces 2-deoxy-D-ribose-1-phosphate during thymidine catabolism, which in turn generates oxygen radical species during the early stages of protein glycation. It was suggested that thymidine led to oxidative stress in thymidine phosphorylase-overexpressing cancer cells, leading to production of stress-induced angiogenic factors, vascular endothelial growth factor, and interleukin-8 and induced matrix metalloproteinase 1, accounting for thymidine phosphorylase-induced angiogenesis $[22,25]$. Upregulation of thymidine phosphorylase by previous external radiotherapy gave rise to development of angiogenesis in the previously irradiated region, leading to hypervascularity and erythema. In fact, the well-recognized palmar-plantar erythrodysethesia (hand-foot syndrome) as a common side effect of capecitabine, may be due to this hypervascularity sequela. Since our patient had received capecitabine continuously for more than 1 year, the accumulative dose of capecitabine might predispose to the development and persistence of her radiation recall. Treatment for radiation recall is most largely conservative with close surveillance. The subsequent irreversible damage of the underlying dermis brought about by prolonged exposure to capecitabine may explain her poor response to symptomatic treatment. Medication like moisturizers, antihistamines or emollients may alleviate symptoms of desquamation, itchiness or warmth. Topical or systemic glucocorticoids may help reduce the inflammatory response but they are usually not curative. Laser therapy, as our patient received as per self-intention, was not proven effective in alleviating the skin condition. Response rates to these symptomatic treatment have been poorly understood as they heavily depend on the pharmacokinetics of the causative agent, duration of use of the causative agent, and whether irreversible skin damage has occurred or not $[2,5]$. Usually the recall reaction may resolve more rapidly after discontinuation of intravenous agents rather than oral treatment. Some reactions to intravenous agents may improve within hours. However, it may takes weeks, months or even longer for the recall reaction to resolve, especially if the causative agent is an oral medication [2].

\section{Conclusions}

In summary, this is the first case of radiation recall related to capecitabine in a patient with recurrent NPC. 
Radiation oncologists should be vigilant of this potential complication associated with capecitabine especially when it is used for a long period of time. Treatment is mainly supportive though significant clinical improvement is not expected.

\section{Acknowledgements}

The authors would like to thank our patient for sharing her presentation for this manuscript.

\section{Funding}

There was no source of funding for this research.

\section{Availability of data and materials}

The data and materials in this manuscript are not made available to any readers since they contain the patient's personal particulars.

\section{Authors' contributions}

$\mathrm{VL}, \mathrm{KL}$, DK and $\mathrm{TL}$ contributed to patient recruitment. VL and $\mathrm{KL}$ prescribed the study medication. All authors contributed to data analysis and interpretation as well as manuscript drafting. All authors read and approval the final manuscript before submission.

\section{Competing interests}

The authors declare that they have no competing interests.

\section{Consent for publication}

Written informed consent was obtained from the patient for publication of this case report and any accompanying images. A copy of the written consent is available for review by the Editor-in-Chief of this journal.

Received: 15 October 2015 Accepted: 10 August 2016

Published online: 07 September 2016

\section{References}

1. Yeo W, Johnson PJ. Radiation-recall skin disorders associated with the use of antineoplastic drugs. Pathogenesis, prevalence, and management. Am J Clin Dermatol. 2000;1:113-6.

2. Camidge R, Price A. Characterizing the phenomenon of radiation recall dermatitis. Radiother Oncol. 2001;59:237-45.

3. Azria D, Magné N, Zouhair A, Castadot P, Culine S, Ychou M, et al. Radiation recall: a well recognized but neglected phenomenon. Cancer Treat Rev. 2005:31:555-70.

4. Caloglu M, Yurut-Caloglu V, Cosar-Alas R, Saynak M, Karagol H, Uzal C. An ambiguous phenomenon of radiation and drugs: recall reactions. Onkologie. 2007;30:209-14.

5. Burris 3rd HA, Hurtig J. Radiation recall with anti-cancer agents. Oncologist. 2010;15:1227-37.

6. Barlési F, Tummino $C$, Tasei AM, et al. Unsuccessful rechallenge with pemetrexed after a previous radiation recall dermatitis. Lung Cancer. 2006:54:423-5.

7. Geyer CE, Forster J, Lindquist D, Chan S, Romieu CG, Pienkowski T, et al. Lapatinib plus capecitabine for HER2-positive advanced breast cancer. N Eng J Med. 2006:355:2733-43.

8. Twelves C, Scheithauer W, McKendrick J, Seitz JF, Van Hazel G, Wong A, et al. Capecitabine versus 5 -fluorouracil/folinic acid as adjuvant therapy for stage III colon cancer: final results from the X-ACT trial with analysis by age and preliminary evidence of a pharmacodynamic marker of efficacy. Ann Oncol. 2012;23:1190-7.

9. Popa EC, Shah MA. Capecitabine in the treatment of esophageal and gastric cancers. Expert Opin Investig Drugs. 2013;22:1645-57.

10. Cunningham D, Chau I, Stocken DD, Valle JW, Smith D, Steward W, et al. Phase III randomized comparison of gemcitabine versus gemcitabine plus capecitabine in patients with advanced pancreatic cancer. J Clin Oncol. 2009;27:5513-8

11. Herrmann R, Bodoky G, Ruhstaller T, Glimelius B, Bajetta E, Schüller J, et al. Gemcitabine plus capecitabine compared with gemcitabine alone in advanced pancreatic cancer: a randomized, multicenter phase III trial of the Swiss Group for Clinical Cancer Research and the Central European Cooperative Oncology Group. J Clin Oncol. 2007;25:2212-7.
12. Chua DT, Sham JS, Au GK. A phase II study of capecitabine in patients with recurrent and metastatic nasopharyngeal carcinoma pretreated with platinum-based chemotherapy. Oral Oncol. 2003;39:361-6.

13. Chua DT, Yiu HH, Seetalarom K, Ng AW, Kurnianda J, Shotelersuk K, et al. Phase II trial of capecitabine plus cisplatin as first-line therapy in patients with metastatic nasopharyngeal cancer. Head Neck. 2012;34:1225-30.

14. Li YH, Wang FH, Jiang WQ, Xiang XJ, Deng YM, Hu GQ, et al. Phase II study of capecitabine and cisplatin combination as first-line chemotherapy in Chinese patients with metastatic nasopharyngeal carcinoma. Cancer Chemother Pharmacol. 2008;62:539-44.

15. Gao Y, Huang HQ, Bai B, Cai QC, Wang XX, Cai QQ. Treatment outcome of docetaxel, capecitabine and cisplatin regimen for patients with refractory and relapsed nasopharyngeal carcinoma who failed previous platinumbased chemotherapy. Expert Opin Pharmacother. 2014;15:163-71.

16. Lee AW, Ngan RK, Tung SY, Cheng A, Kwong DL, Lu TX, et al. Preliminary results of trial NPC-0501 evaluating the therapeutic gain by changing from concurrent-adjuvant to induction-concurrent chemoradiotherapy, changing from fluorouracil to capecitabine, and changing from conventional to accelerated radiotherapy fractionation in patients with locoregionally advanced nasopharyngeal carcinoma. Cancer. 2015;121:1328-38.

17. Wallenborn 3rd PA, Postma DS. Radiation recall supraglottitis. A hazard in head and neck chemotherapy. Arch Otolaryngol. 1984;110:614-7.

18. Wiatrak BJ, Myer 3rd CM. Radiation recall supraglottitis in a child. Am J Otolaryngol. 1991;12:227-9.

19. van Vloten WA, Hermans J, van Daal WA. Radiation-induced skin cancer and radiodermatitis of the head and neck. Cancer. 1987:59:411-4.

20. Ortmann E, Hohenberg G. Treatment side effects Case 1. Radiation recall phenomenon after administration of capecitabine. J Clin Oncol. 2002;20:3029-30

21. Ghosal N, Misra V. A case of capecitabine-induced hyperpigmentation and radiation recall phenomenon. Clin Oncol (R Coll Radiol). 2009;21:632.

22. Saif MW, Black G, Johnson M, Russo S, Diasio R. Radiation recall phenomenon secondary to capecitabine: possible role of thymidine phosphorylase. Cancer Chemther Pharmacol. 2006;58:771-5.

23. Furukawa T, Yoshimura A, Sumizawa T, Haraguchi M, Akiyama S, Fukui K, et al. Angiogenic factor. Nature. 1992;356:668.

24. Jeffrey G, Truss C, Saif MW. Radiation recall syndrome associated with capecitabine. J Appl Res. 2004;4:495-8.

25. Sawada N, Ishikawa T, Sekiguchi F, Tanaka Y, Ishitsuka H. X-ray irradiation induces thymidine phosphorylase and enhances the efficacy of capecitabine (Xeloda) in human cancer xenografts. Clin Cancer Res. 1999;5:2948-53.

\section{Submit your next manuscript to BioMed Central} and we will help you at every step:

- We accept pre-submission inquiries

- Our selector tool helps you to find the most relevant journal

- We provide round the clock customer support

- Convenient online submission

- Thorough peer review

- Inclusion in PubMed and all major indexing services

- Maximum visibility for your research

Submit your manuscript at www.biomedcentral.com/submit
) Biomed Central 